\title{
KOMPARASI ANGGARAN OBJEK WISATA PULAU PASUMPAHAN DAN PULAU ANGSO DUO PROVINSI SUMATERA BARAT
}

\author{
Dela Oktaviani Chandra ${ }^{1}$, Yurni Suasti ${ }^{2}$, Fitriana Syahar ${ }^{2}$ \\ Program Studi Pendidikan Geografi, \\ Fakultas Ilmu Sosial, Universitas Negeri Padang \\ Email: delaoktavianichandra95@gmail.com
}

\begin{abstract}
Abstrak
Tujuan penelitian ini mendeskripsikan: perbandingan pemasukan dana dan alokasi dana antara objek wisata Pulau Pasumpahan dan Pulau Angso Duo dari tahun 2015-2017. Data yang digunakan adalah data sekunder dari tahun 2015-107. Penelitian ini menemukan alokasi anggaran Pulau Pasumpahan tahun 2005 adalah Rp. 225.000.000,00 naik menjadi Rp. 400.000.000 pada tahun 2016 dengan kenaikan 56,25\%, kemudian naik lagi menjadi Rp. 895.000.000,00 pada tahun 2017 dengan kenaikan 44,69\%. Sedangkan pemasukan anggaran Pulau Angso Duo pada tahun 2015 adalah Rp. 228.000.000,00 naik menjadi Rp. 277.000.000,00 pada tahun 2016 dengan kenaikan 82,31\% , kemudian naik lagi menjadi Rp. 395.000.000,00 pada tahun 2017 dengan kenaikan 70,12\%. Bila dibandingkan kedua objek tersebut, alokasi anggaran lebih besar di Pulau Pasumpahan dari pada di Pulau Angso Duo tetapi bila dibandingkan persentase, kenaikannya lebih tinggi di Pulau Angso Duo dari pada di Pulau Pasumpahan. Alokasi dana Pulau Pasumpahan untuk 6 asset sedangkan Pulau Angso Duo untuk 5 asset, sehingga dana Pulau Pasumpahan lebih lengkap dari pada Pulau Angso Duo.
\end{abstract}

Kata Kunci: Komparasi Anggaran, Aset, Objek Wisata.

\begin{abstract}
The purpose of this study is to describe: the comparison of fund revenues and allocation of funds between Pasumpahan Island and Angso Duo Island tourist objects from 2015-2017. The data used is secondary data from 2015-107. This study found that the 2005 Pasumpahan Island budget allocation was Rp. 225,000,000.00 rose to Rp. 400,000,000 in 2016 with an increase of 56.25\%, then rose again to Rp. 895,000,000.00 in 2017 with an increase of $44.69 \%$. While the revenue of Angso Duo Island in 2015 was Rp. 228,000,000.00 rose to Rp. $277,000,000.00$ in 2016 with an increase of $82.31 \%$, then rose again to $R p$. 395,000,000.00 in 2017 with an increase of $70.12 \%$. When compared to the two objects, the budget allocation is greater in Pasumpahan Island than in Angso Duo Island but when compared to the percentage, the increase is higher in Angso Duo Island than in Pasumpahan Island. Pasumpahan Island funds allocation for 6 assets while Angso Duo Island is for 5 assets, so Pasumpahan Island funds are more complete than Angso Duo Island.
\end{abstract}

Keywords: Budget comparation, Asset, Tourist attaction.

\footnotetext{
${ }^{1}$ Mahasiswa Program Studi Pendidikan Geografi untuk wisuda September 2018

${ }^{2}$ Dosen Jurusan Geografi Fakultas Ilmu Sosial Universitas Negeri Padang dengan Pembimbing I

Dra. Yurni Suasti, M.Si dan Pembimbing II Fitriana Syahar,S.Si,M.Si
} 


\section{PENDAHULUAN}

Pulau Pasumpahan dan Angso Duo merupakan destinasi wisata yang terdapat di Sumatera Barat. Pulau Pasumpahan dan Angso Duo terletak di daerah Padang dan Pariaman. Pulau Pasumpahan terletak di kecamatan Bungus Teluk Kabung yang memiliki jarak tempuh $200 \mathrm{~m}$ dari teluk Bungus Padang. Dengan koordinat terletak pada 01'07'04" LS dan 100'22'03" BT. Kecamatan Bungus Teluk Kabung berada dalam jarak $12 \mathrm{Km}$ dari pusat kota dan berbatasan langsung dengan Kabupaten Pesisir Selatan. Sedangkan Pulau Angso Duo terletak di kota Pariaman yang memiliki jarak tempuh sekitar $65 \mathrm{~km}$ dari kota padang. Secara administrasi Pulau Angso Duo terletak di Kecamatan Pariaman Tengah, Kota Pariaman. secara astronomis, Kecamatan Pariaman Tengah terletak antara 0'37'30 LS dan 100'7'30 BT. Kecamatan Pariaman Tengah terletak di jantung Kota Pariaman dengan luas daerah wilayah $15,68 \mathrm{~km}$.

Luas pulau Pasumpahan sekitar 16,9 hektar. Disisi barat pulau terdapat area terumbu karang 16,0 hektar. Luas Pulau Angso Duo sekitar 5 hektar yang terdiri dari 1,2 hektar hamparan pasir dan 3,8 hektar kawasan vegetasi dan luas terumbu karang sekitar 16,4 hektar.

Pulau Pasumpahan dan Angso Duo memiliki keindahan alam yang menjadi ciri khas dari masing-masing pulau. Keindahan alam pada Pulau Pasumpahan terkenal dengan keindahannya dan perairan jernih yang memiliki tiga degradasi warna yaitu bening dipinggir pantai, kehijauan ditengahnya, dan kebiruan untuk lebih ke tengah lautan. Keindahan alam yang dapat dilihat dari pulau Angso Duo adalah disepanjang bibir pantai terdapat pasir putih yang indah, airnya yang begitu jernih dan cukup tenang, keindahan terumbu karang yang masih sangat terjaga dan beberapa biota laut lainnya seperti ikan hias yang menghiasi pemandangan.

Potensi-potensi yang ada di kedua objek wisata tersebut haruslah dikekola dengan cara yang tepat. Salah satunya yaitu melakukan pengembangan agar objek wisata tersebut tidak ketinggalan dengan pulau-pulau yang baru. Sehingga perlu beberapa upaya yang dilakukan oleh pengelola objek wisata yaitu dengan cara mencari anggaran untuk melakukan pengembangan terhadap objek wisata tersebut. Anggaran yang dimaksud dapat diperoleh oleh beberapa sumber seperti pihak pemerintah, pihak wisata maupun masyarak sendiri.

Pemasukan anggaran ini akan sangat mempengaruhi perkembangan fasilitas di pulau tersebut. Semakin besar pemasukan anggaran yang diperoleh dari Pemerintah, Swasta dan Masyarakat maka semakin besar pula peluang untuk mengembangkan fasilitas pulau. Dengan demikian maka pengelolaan pulau harus menjalin hubungan yang erat dan baik terhadap para investor dari Pemerintah, Swasta dan Masyarakat. 
Pengembangan objek wisata dapat berjalan dengan baik apabila pengelolaannya dapat dilakukan dengan sebaik-baiknya. Pengelolaan objek wisata sangat berpengaruh terhadap perkembangan kepariwisataan itu sendiri karena lancar tidaknya suatu objek wisata sangat ditentukan oleh bagaimana pengelolaan yang dilakukan. Sehubungan dari masalah diatas, maka penulis tertarik untuk mengkaji lebih dalam mengenai

\section{"Komparasi Anggaran Objek Wisata Pulau Pasumpahan dan Pulau Angso Duo Provinsi Sumatera Barat"}

Istilah pengembangan menurut Bakaruddin (1987:67), menyatakan bahwa pengembangan yaitu sebagai usaha-usaha yang dilakukan manusia sebagai subjek untuk mengarahkan perubahan yang terjadi pada suatu objek. Sedangkan Suryobroto (1990) mengartikan pengembangan sebagai usaha yang dilakukan oleh manusia untuk mengembangkan personalia dan fasilitas terhadap suatu objek sehingga kegiatan tersebut dapat dilaksanakan dengan baik dan optimal. Menurut Suwantoro (2000), menyatakan pengembangan bertujuan untuk mengembangkan produk yang pelayanan yang berkualitas, seimbang, dan bertahan.

Berdasarkan pendapat ahli di atas, dapat disimpulkan bahwa pengembangan merupakan upayaupaya yang dilakukan dengan tujuan memajukan, memperbaiki, dan meningkatkan kondisi kepariwisataan suatu objek dan daya tarik wisata sehingga mampu menjadi mapan dan ramai untuk dikunjungi oleh wisatawan serta mampu memberikan suatu manfaat baik bagi masyarakat di sekitar objek.

Hunziker (dalam Bakaruddin, 1983:57) menyatakan bahwa pariwisata adalah salah satu bentuk interaksi sosial yang ditimbulkan oleh kunjungan orang-orang asing/lokal dan bukan penduduk setempat.

Sejalan dengan itu Suwantoro (1997:3) mengemukakan bahwa pariwisata merupakan suatu proses kepergian sementara dari seseorang atau lebih menuju tempat lain di luar tempat tinggalnya.

Menurut Intosh (dalam Muljadi, 2009:8), pariwisata adalah keseluruhan kegiatan yang berhubungan dengan keluar masuk, tinggal, dan pergerakan penduduk asing di dalam atau di luar suatu negara, kota atau wilayah tertentu.

Berdasarkan

beberapa pendapat para ahli di atas, dapat disimpulkan bahwa pariwisata adalah perjalanan yang dilakukan oleh seseorang atau sekelompok dari daerah asal ke daerah tujuan dengan tujuan bersenang-senang bukan bekerja dengan waktu minimal 24 jam.

Jamaris (1991:1), menyatakan bahwa objek wisata merupakan segala sesuatu yang dapat dilihat, dinikmati, dan menimbulkan kesan tersendiri seseorang apabila didukung oleh sarana dan prasarana yang memadai.

Wihoho

(1990:551)

mengartikan objek wisata sebagai sesuatu yang dapat menjadi daya tarik 
bagi seseorang atau calon wisatawan untuk mau berkumpul ke suatu daerah tujuan wisata.

Menurut Gamal (1997:6), objek wisata merupakan potensi yang menjadi pendorong kehadiran wisatawan kesuatu daerah tujuan wisata, disamping itu juga yang menjadi daya tariknya berupa:

a) Adanya sumber daya yang dapat menimbulkan rasa senang, indah, nyaman, dan bersih.

b) Adanya aksebilitas yang tinggi untuk dapat mengunjunginya.

c) Adanya ciri khusus atau spesifikasi yang bersifat langka

d) Adanya sarana dan prasarana penunjang untuk melayani para wisatawan yang hadir.

e) Objek wisata alam mempunyai daya tarik tinggi karena keindahan alam, pegunungan, sungai, danau, pantai pasir, hutan, dan sebagainya.

f) Objek wisata budaya mempunyai daya tarik tinggi karena memiliki nilai khusus dalam bentuk atraksi kesenian, upacara adat, nilai luhur yang terkandung dalam suatu objek buah karya manusia pada masa lampau.

Sejalan dengan itu, Kosasih (1987:3) menerangkan bahwa objek wisata alam adalah suatu tempat dimana kita dapat bergembira, bersenang-senang, dan bersukaria tanpa ada gangguan dari pihak lainnya dengan batasan pemandangan alam (pantai, danau, dan pegunungan).
Dari pendapat para ahli di atas, dapat disimpulkan bahwa objek wisata alam adalah tempat dimana kita dapat menikmati keindahan dan keunikan yang ada di alam baik itu yang bersifat hayati maupun non hayati.

Yoeti (1997:33), menyatakan alasan perlunya pengembangan pariwisata atau objek wisata sebagai berikut:

a. Pengembangan pariwisata pada suatu daerah tujuan wisata selalu akan diperhitungkan keuntungan dan manfaat bagi rakyat banyak

b. Pengembangan pariwisata lebih banyak bersifat nonekonomis sebab motivasi utama wisatawan mengunjungi suatu kawasan objek wisata adalah untuk menyaksikan dan melihat keindahan alam daerah yang dikunjungi

c. Untuk menghilangkan kepanikan berpikir, mengurangi salah pengertian dan mengetahui tingkah laku wisatawan yang berkunjung terutama bagi masyarakat di daerah tujuan wisata yang bersangkutan.

Pengembangan suatu objek wisata menjadi daerah tujuan wisata yang dapat diandalkan ditentukan oleh berbagai produk wisata yang harus dimiliki daerah tersebut, faktorfaktor tersebut antara lain: adanya objek yang disaksikan dan mempunyai daya tarik khusus serta berbeda dengan daerah lainnya, adanya atraksi wisata yang disajikan untuk wisatawan, adanya oleh-oleh 
khusus dari kawasan objek wisata yang akan dibeli dan dibawa pulang, serta didukung oleh sarana dan prasarana yang memadai seperti restoran, penginapan, transportasi, komunikasi dan lainnya (Khohyat, 1980:58).

Dari pendapat para ahli di atas, dapat disimpulkan bahwa perlu adanya keterpaduan dan kerjasama yang baik antara unsur-unsur kepariwisataan dalam upaya pengembangan objek wisata. dalam hal ini, peranan pengelola dan masyarakat sangatlah penting.

Menurut Shim (200:4) jenis anggaran terdiri dari:

a) anggaran operasi (operating budget) digunakan untuk menghitung biaya yang diproduksi atau jasa yang dihasilkan.

b) anggaran keuangan (financial budget) dapat digunakan untuk memeriksa kondisi keuangan dari devisi, yaitu dengan memeriksa rasio aktiva terhadap kewajiban, arus kas, modal kerja, profitabilitas dan statistik lainnya yang berhubungan dengan kesehatan keuangan.

c) anggaran cas (cash budget) digunakan untuk perencanaan dan pengendalian terhadap kas.

d) anggaran pengeluaran modal (capital expenditure budget) berisi proyek-proyek penting jangka panjang dan modal yang harus dibeli.

e) anggaran suplemental (supplementalbudget) memberi pendanaan tambahan untuk item- item yang tidak termasuk dalam anggaran reguler.

f) anggaran bracket (bracket budget) merupakan rencana kontinjensi dimana biaya diprediksi pada jumlah yang lebih tinggi dan lebih rendah dari pada angka dasarnya.

g) anggaran stretch merupakan anggaran yang optimistis dan biasanya digunakan untuk penjualan yang diproyeksikan tinggi pencapaiannya.

h) Anggaran strategis mengintegrasikan perencanaan strategis dan pengendalian penganggaran.

i) Anggaran target merupakan rencana yang mengkategorikan pengeluaran-pengeluaran utama dan menyesuaikannya dengan tujuan divisi.

j) Anggaran program digunakan untuk produk dan jasa. Produkproduk yang ada dan yang baru diperiksa.

Menurut Shim (2004:7) Langkah-langkah yang harus diikuti dalam penganggaran yaitu:

1. Penetapan tujuan.

2. Pengevaluasian sumber-sumber daya yang tersedia.

3. Negosiasi antara pihak-pihak yang terlibat mengenai angkaangka anggaran.

4. Pengkoordinasian dan peninjauan komponen.

5. Persetujuan akhir.

6. Pendistribusian anggaran yang disetujui. 
Menurut Shim (200:4) jenis anggaran terdiri dari: (a) anggaran operasi (operating budget) digunakan untuk menghitung biaya yang diproduksi atau jasa yang dihasilkan. (b) anggaran keuangan (financial budget) dapat digunakan untuk memeriksa kondisi keuangan dari devisi, yaitu dengan memeriksa rasio aktiva terhadap kewajiban, arus kas, modal kerja, profitabilitas dan statistik lainnya yang berhubungan dengan kesehatan keuangan. (c) anggaran cas (cash budget) digunakan untuk perencanaan dan pengendalian terhadap kas. (d) anggaran pengeluaran modal (capital expenditure budget) berisi proyekproyek penting jangka panjang dan modal yang harus dibeli. (e) anggaran suplemental (supplementalbudget) memberi pendanaan tambahan untuk item-item yang tidak termasuk dalam anggaran reguler. (f) anggaran bracket (bracket budget) merupakan rencana kontinjensi dimana biaya diprediksi pada jumlah yang lebih tinggi dan lebih rendah dari pada angka dasarnya. (g) anggaran stretch merupakan anggaran yang optimistis dan biasanya digunakan untuk penjualan yang diproyeksikan tinggi pencapaiannya. (h) anggaran strategis mengintegrasikan perencanaan strategis dan pengendalian penganggaran. (i) anggaran target merupakan rencana yang mengkategorikan pengeluaranpengeluaran utama dan menyesuaikannya dengan tujuan divisi. (j) anggaran program digunakan untuk produk dan jasa.
Produk-produk yang ada dan yang baru diperiksa.

Selanjutnya menurut Shim (2004:7) Langkah-langkah yang harus diikuti dalam penganggaran yaitu: (1) Penetapan tujuan. (2) Pengevaluasian sumber-sumber daya yang tersedia. (3) Negosiasi antara pihak-pihak yang terlibat mengenai angka-angka anggaran.

Pengkoordinasian dan peninjauan komponen. (5) Persetujuan akhir. (6) Pendistribusian anggaran yang disetujui.

\section{METODE PENELITIAN}

Jenis penelitian ini adalah deskriptif kualitatif. Jenis data yaitu data sekunder, yang mana data tersebut telah dikumpulkan oleh lembaga pengumpulan data dan dipublikasikan kepada masyarakat pengguna data yang dikumpulkan dengan observasi, wawancara dan angket (kuisioner).

\section{HASIL DAN PEMBAHASAN \\ Investasi Dana Pemasukan Pulau Pasumpahan}

Secara Geografis Pulau

Pasumpahan terletak diwilayah administratif Kelurahan Teluk Kabung Selatan (Sungai Pisang), Kecamatan Bungus Teluk Kabung, Kota Padang. Dengan koordinat terletak pada 01'07'04" LS dan 100'22'03" BT. Kecamatan

Bungus Teluk Kabung berada dalam jarak $12 \mathrm{Km}$ dari pusat kota dan berbatasan langsung dengan Kabupaten Pesisir Selatan. 
Bungus Teluk Kabung merupakan daerah datar dan sebagian berbukit yang memiliki Pulau dengan Pantai berpasir putih yang ditumbuhi dengan beberapa jenis tumbuhan tingkat tinggi seperti kelapa, semak dan rumput.

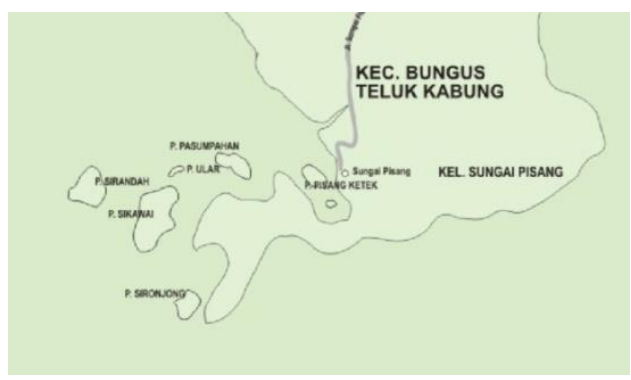

Gambar 1

\section{Peta Pulau Pasumpahan}

Sumber: Dinas Pariwisata Kota

Padang, 2017

Berdasarkan informasi dari masyarakat setempat, sejarah Pulau Pasumpahan bisa dibilang seperti cerita-cerita dongeng. Cerita sejarah Pulau Pasumpahan ini memiliki versi cerita yang berbeda. Sebagian masyarakat setempat mengatakan sejarah Pulau Pasumpahan ini berawal dari kisah seorang anak yang durhaka kepada orang tuanya. Selain itu, ada juga yang mengatakan bahwa Pulau Pasumpahan ini dahulunya merupakan tempat bersumpah para orang tua terdahulu atas perbuatan yang melanggar aturan adat dan agama. Jadi dapat disimpulkan bahwa Pulau Pasumpahan ini memang sudah ada dari sejak dahulunya.

Kondisi umum Pulau Pasumpahan merupakan Pulau datar dengan sebagian daerah yang berbukit dengan pantai berpasir putih serta memiliki beberapa tumbuhan tinggi seperti pohon kelapa, semak dan rumput. Pulau Pasumpahan terletak tidak terlalu jauh dari Pulau Pisang dan Pulau Mandeh. Disepanjang bibir Pantai Pulau Pasumpahan ini memiliki pasir putih yang sangat bersih dan lembut. Pada sebagian area pulau terdapat bukit yang biasa dijelajahi oleh para wisatawan. Bukan saja keadaan Pantai yang terjaga, area perbukitan pada Pulau ini juga terjaga keamanan dan kebersihannya. Pulau Pasumpahan sangat mudah dijangkau dan ditemui oleh para wisatawan.

Potensi pengembangan yang dimiliki Pulau Pasumpahan terletak pada keindahan Pasir Putih serta keindahan lautnya. Selain memiliki pasir putih yang lembut serta bersih, pulau ini juga memiliki warna air laut yang sangat menawan. Air laut di Pulau Pasumpahan ini memiliki tiga warna yang indah. Warna bening dibagian tepi laut, warna hijau didepannya serta warna biru dibagian tengah permukaan laut. Dengan pasir putih yang bersih dan air laut yang jernih menjadikan para wisatawan sangat nyaman untuk berlibur ke pulau ini.

Pulau Pasumpahan memiliki fasilitas yang mendukung agar objek wisata Pulau Pasumpahan lebih diminati oleh mancanegara dan pengunjung di berbagai daerah. Dengan adanya fasilitas-fasilitas yang telah disediakan menambah minat pengujung untuk semakin menjadikan Pulau Pasumpahan sebagai pilihan untuk berwisata. fasilitas-fasilitas yang ada di objek wisata Pulau Pasumpahan seperti: (1) Perahu/speed 
boat. Perahu tersebut disewa oleh pengunjungsebagai akses mudah menuju Pulau Pasumpahan. pengunjung dapat mengunjungi Pulau Pasumpahan dengan menggunakan perahu dan speed boat, kalau dari Sungai Pisang memakan waktu 15-20 menit, yaitu dengan tarif $\mathrm{Rp}$ 50.000/60.000 per orang. sedangkan jika naiknya dari Bungus Selatan tarifnya per paket, yaitu 1 orang 250 keatas, namun sudah lengkap dengan makanannya langsung. (2) Banana Boat dan Donat Boat. Merupakan salah satu fasilitas hiburan yang ada di Pulau Pasumpahan, dengan tarif per orang yaitu Rp. 30.000, sedangkan Jet Sky tarifnya lebih mahal yaitu Rp 100.000/orang. alat penyelam lainnya seperti snorkling dan sekaligus kamera dengan tarif Rp 50.000/orang. (3) Toilet.

Pulau Pasumpahan memiliki 8 toilet yang disediakan oleh Pemerintah untuk pengunjung yang melakukan MCK dan mandi sehabis bermain ombak dan sekaligus tempat ganti pakaian sehabis mandi. (4) Penginapan. Pulau Pasumpahan memiliki rumah penginapan dan juga penyewaan tenda bagi yang pergi camping. Pulau Pasumpahan memiliki 10 kamar penginapan dengan tarif Rp.300.000 sedangkan sewa tenda sehari semalam dengan tarif Rp. 70.000. Selain itu, di Pulau Pasumpahan juga terdapat pondok lesehan dengan tarif Rp. 150.000 sehari semalam. Untuk pengunjung yang bermalam di pulau, juga bisa membawa tenda masing-masing dari rumah. (5) Musholla. Pulau
Pasumpahan memiliki 1 musholla yang disediakan oleh pemilik Pulau Pasumpahan untuk para pengunjung agar pengunjung dapat melakukan ibadahnya.

Pulau Pasumpahan merupakan aset yang dimiliki oleh Pemerintah Kota Padang. agar Pulau Pasumpahan dapat berkembang dengan baik, oleh karena itu Pemerintah Kota Padang menyerahkan Pulau Pasumpahan dikelola oleh beberapa instansi yang mana instansi ini mempunyai hak-hak batas kelola, yaitu Dinas Kebudayaan dan Pariwisata dengan Dinas Kelautan dan Perikanan (DKP). Selain itu, Pengelolaan Pulau Pasumpahan juga diserahkan kepada beberapa orang masyarakat setempat yang ditunjuk sebagai penjaga keamanan dan kebersihan Pulau ini.

Dari segi wisata, Pulau Pasumpahan dikelola oleh Dinas Kebudayaan dan Pariwisata dengan tugas mengelola tiket masuk, pengelolaan atraksi wisata, pembangunan, serta promosi. Semua pengelolaan yang dilakukan akan dipromosikan melalui website, media sosial, internet, brosur serta eventevent yang diadakan di Pulau tersebut. Sedangkan Dinas Kelautan dan Perikanan (DKP) bertugas untuk memelihara keindahan laut dan pulau, serta menjaga biota laut yang ada di Pulau tersebut. 
Tabel 1

Alokasi Aset Pulau Pasumpahan Tahun 2015-2017

\begin{tabular}{lccc}
\hline Sumber & \multicolumn{3}{c}{ Pulau Pasumpahan } \\
\cline { 2 - 4 } & \multicolumn{3}{c}{ Tahun } \\
\cline { 2 - 4 } & $\mathbf{2 0 1 5}$ & $\mathbf{2 0 1 6}$ & $\mathbf{2 0 1 7}$ \\
\hline Pmt & 60.000 .000 & 150.000 .000 & 175.000 .000 \\
\hline Swt & 120.000 .000 & 180.000 .000 & 170.000 .000 \\
\hline Masy & 45.000 .000 & 70.000 .000 & 550.000 .000 \\
\hline & $\mathbf{2 2 5 . 0 0 0 . 0 0 0}$ & $\mathbf{4 0 0 . 0 0 0 . 0 0 0}$ & $\mathbf{8 9 5 . 0 0 0 . 0 0 0}$
\end{tabular}

Sumber: Dinas Pariwisata Kota Padang, 2017

Anggaran pemasukan pada

Pulau Pasumpahan seetiap tahunnya semakin meningkat. Pada tahun 2015 pemasukan anggaran sebesar Rp. 225.000.000. Kemudian meningkat lagi pada tahun 2016 dengan pemasukan anggaran yang di peroleh sebesar Rp. 400.000.000. Pada tahun 2017 Pulau Pasumpahan memiliki peningkatan pemasukan anggaran yang diperoleh sebesar Rp. 895.000.000. Dari tahun 2015-2017 jumlah kunjungan dan anggaran pemasukan pada Pulau Pasumpahan semakin meningkat

Pemasukan anggaran yang diperoleh dari Pemerintah merupakan hasil kunjungan wisatawan yang datang. Dengan semakin banyaknya wisatawan berkunjung maka semakin besar pula anggaran pemasukan yang diperoleh. Selain dari itu, anggaran pemasukan yang diperoleh dari Swasta merupakan hasil kerjasama yang dilakukan pihak Pemerintah Daerah dan Swasta guna untuk pengembangan Pulau Pasumpahan tersebut. kerjasama yang dilakukan Pemerintah Daerah dan Swasta merupakan hasil dari promosi yang di sebarkan melalui website, dan media sosial. Anggaran pemasukan yang diperoleh dari masyarakat merupakan hasil dari pembagian pendapatan yang diperoleh. Setiap masyarakat yang berdagang di area Pulau akan dikenakan biaya pemotongan harga sewa sebesar $10 \%$ setiap bulannya

\section{Tabel 2}

Anggaran Pemasukan

Pulau Pasumpahan Tahun 2015-2017

\begin{tabular}{|c|c|c|c|c|}
\hline $\begin{array}{l}\text { Sumber } \\
\text { Dana } \\
\text { Anggar } \\
\text { an }\end{array}$ & $\begin{array}{l}\text { Dana } \\
\text { Anggaran }\end{array}$ & $\begin{array}{l}\text { Aset Pulau } \\
\text { Pasumpah } \\
\text { an }\end{array}$ & Jumlah & Harga \\
\hline \multirow[t]{2}{*}{ Pmt } & \multirow[t]{2}{*}{60.000 .000} & Speed Boat & $2 \mathrm{bh}$ & 46.000 .000 \\
\hline & & Mesin $40 \mathrm{PK}$ & $1 \mathrm{bh}$ & 14.000 .000 \\
\hline \multirow[t]{3}{*}{ Sws } & \multirow[t]{3}{*}{120.000 .000} & BananaBoat & $6 \mathrm{bh}$ & 93.000 .000 \\
\hline & & Pelampung & $40 \mathrm{bh}$ & 8.800 .000 \\
\hline & & $\begin{array}{c}\text { Promosi(FB,Twitter, } \\
\text { Blog) }\end{array}$ & & 18.200 .000 \\
\hline \multirow[t]{2}{*}{ Masy } & \multirow[t]{2}{*}{45.000 .000} & $\begin{array}{c}\text { Promosi (instragram, } \\
\text { brodur) }\end{array}$ & & 7.000 .000 \\
\hline & & Jet ski & $2 \mathrm{bh}$ & 38.000 .000 \\
\hline \multirow[t]{3}{*}{ Pmt } & \multirow[t]{3}{*}{150.000 .000} & Flying fish & $5 \mathrm{bh}$ & 23.000 .000 \\
\hline & & Donat Boat & $3 \mathrm{bh}$ & 70.500 .000 \\
\hline & & Penginapan & $2 \mathrm{bh}$ & 56.500 .000 \\
\hline \multirow[t]{3}{*}{ Sws } & \multirow[t]{3}{*}{180.000 .000} & Penginapan & $3 \mathrm{bh}$ & 11.300 .000 \\
\hline & & Speed Boat & $3 \mathrm{bh}$ & 69.000 .000 \\
\hline & & Tenda & $60 \mathrm{bh}$ & 99.700 .000 \\
\hline \multirow[t]{4}{*}{ Masy } & \multirow[t]{4}{*}{70.000 .000} & Bangku & 8 bh & 19.000 .000 \\
\hline & & Toilet & $4 \mathrm{bh}$ & 22.000 .000 \\
\hline & & Mushola & $1 \mathrm{bh}$ & 13.000 .000 \\
\hline & & Promosi & & 16.000 .000 \\
\hline \multirow[t]{4}{*}{ Pmt } & \multirow[t]{4}{*}{175.000 .000} & Pelampung & $70 \mathrm{bh}$ & 15.400 .000 \\
\hline & & Speed Boat & $2 \mathrm{bh}$ & 46.000 .000 \\
\hline & & Tenda & 40bh & 66.000 .000 \\
\hline & & Jet ski & $3 \mathrm{bh}$ & 47.000 .000 \\
\hline \multirow[t]{5}{*}{ Sws } & \multirow[t]{5}{*}{170.000 .000} & Penginapan & $3 \mathrm{bh}$ & 11.300 .000 \\
\hline & & Toilet & $4 \mathrm{bh}$ & 22.000 .000 \\
\hline & & Promosi & & 18.000 .000 \\
\hline & & Speed boad & $3 \mathrm{bh}$ & 69.000 .000 \\
\hline & & Mesin $40 \mathrm{PK}$ & $3 \mathrm{bh}$ & 49.000 .000 \\
\hline \multirow[t]{6}{*}{ Masy } & \multirow[t]{6}{*}{550.000 .000} & Donat Boat & $8 \mathrm{bh}$ & 11.750 .000 \\
\hline & & Banana Boat & $4 \mathrm{bh}$ & 62.000 .000 \\
\hline & & Jet ski & $4 \mathrm{bh}$ & 62.700 .000 \\
\hline & & Flying Fish & 5 bh & 23.000 .000 \\
\hline & & Water Dohut & & 45.000 .000 \\
\hline & & Water Bufterfly & & 35.000 .000 \\
\hline
\end{tabular}

Investasi Dana Pemasukan Pulau Angso Duo

Secara administrasi Pulau

Angso Duo terletak di Kecamatan

Pariaman Tengah, Kota Pariaman. secara astronomis, Kecamatan Pariaman Tengah terletak antara 
0'37'30 LS dan 100'7'30 BT. Kecamatan Pariaman Tengah terletak di jantung Kota Pariaman dengan luas daerah wilayah $15,68 \mathrm{~km}$.

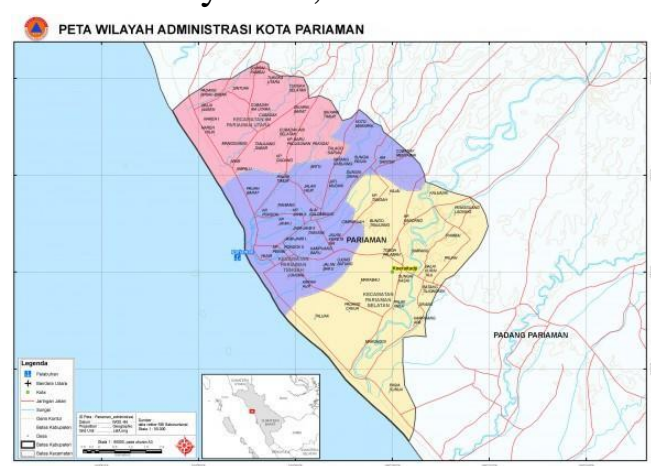

Gambar 2

Peta Pulau Angso Duo

Sumber: Dinas Pariwisata Kota Padang, 2017

Objek wisata Pulau Angso Duo dipercaya oleh masyarakat Pariaman sebagai tempat persinggahan bagi para ulama besar yang menyebarkan agama islam di Minangkabau, contohnya di Pulau tersebut terdapat peninggalan sejarah seperti makam ulama besar yang panjangnya lebih 4 meter, sebuah surau yang bernama Surau Katik Sangko dan sebuah sumur tua. Makam di Pulau tersebut yang dahulunya bisa berpindah-pindah sehingga makam tersebut diberi semen.

Potensi pengembangan Pulau Angso Duo terletak pada Pasir Putih serta makam sejarah yang terletak di pulau ini. Dengan pasir putih yang indah, menjadikan daya tarik wisatawan untuk berkunjung. Selain itu makam bersejarah di pulau ini juga menjadi alasan utama para wisatawan untuk berkunjung. Dengan adanya makam bersejarah tersebut wisatawan dapat menikmati liburan serta dapat menambah wawasan.
Sarana dan Prasarana yang ada di Pulau Angso ini sangat beragam, dan merupakan daya tarik yang menarik perhatian para wisatawan untuk datang berkunjung. Sarana prasarana di pulau ini merupakan faktor pendukung pengembangan Pulau Angso Duo ini. Sarana dan prasarana Pulau Angso Duo seperti:

1) Dermaga Terapung

Dermaga terapung ini merupakan aset dari Dinas Kelautan dan Perikanan Kota Pariaman yang dibangun pada tahun 2015. Dermaga ini sangat membantu para awak kapal untuk menurunkan penumpang dan memakirkan kapalnya.

Dengan adanya dermaga terapung ini penumpang dapat turun dengan nyaman ke dermaga tanpa perlu meloncat ke tepian pantai seperti debelumnya dan awak kapal pun lebih mudah menurunkan penumpang.

2) Penginapan

Penginapan ini dibangun dari anggaran pemasukan yang diperoleh dari Pemerintah Daerah. Dengan adanya pembangunan tempat penginapan tersebut menjadikan Pulau Angso Duo semakin berkembang. Jika pengunjung tidak puas satu hari di Pulau ini, pengunjung dapat menginap di tempat penginapan yang sudah disediakan dengan tarif Rp. 300.000/hari.

3) Rumah Jaga/Pos Jaga

Dari tahun ke tahun selalu ada peningkatan yang dapat dilihat di Pulau Angso Duo ini. Seperti pos jaga yang baru dibangun pada tahun 2015 yang berjumlah 1 unit. 
4) Kamar Bilas/Toilet

Kamar bilas merupakan fasilitas yang disediakan oleh DKP hal ini ditujukan untuk wisatawan yang berkunjung ke pulau ini. DKP menyediakan kamar bilas sebanyak 2 unit, satu unit pertama dibangun pada tahun 2010 dengan empat pintu. Dan 1 unit kedua dibangun pada tahun 2015 sebanyak empat pintu. Kebersihan kamar bilas ini menjadi tanggung jawab penjaga pulau.

Pulau Angso Duo merupakan aset yang dimiliki oleh Pemerintah Kota Pariaman. agar Angso Duo dapat berkembang dengan baik, oleh karena itu Pemerintah Kota Pariaman menyerahkan Pulau Angso Duo dikelola oleh beberapa instansi yang mana instansi ini mempunyai hak-hak batas kelola, yaitu Dinas Kebudayaan dan Pariwisata dengan Dinas Kelautan dan Perikanan (DKP). Selain itu, Pengelolaan Pulau Angso Duo juga diserahkan kepada beberapa orang masyarakat setempat yang ditunjuk sebagai penjaga keamanan dan kebersihan Pulau ini.

Dari segi wisata, Pulau Angso Duo dikelola oleh Dinas Kebudayaan dan Pariwisata dengan tugas mengelola tiket masuk, pengelolaan atraksi wisata, pembangunan, serta promosi. Semua pengelolaan yang dilakukan akan dipromosikan melalui website, media sosial, internet, brosur serta event-event yang diadakan di Pulau tersebut. Sedangkan Dinas Kelautan dan Perikanan (DKP)bertugas untuk memelihara keindahan laut dan pulau, serta menjaga biota laut yang ada di Pulau tersebut.

Adanya kerjasama Pemerintah dengan Dinas Kebudayaan dan Pariwisata serta Dinas Kelautan dan Perikanan (DKP). Sangat membantu dalam pengembangan dan mempromosikan Pulau Pasumpahan ini. Dengan pengelolaan yang baik menjadikan para investor yang datang dari swasta ikut serta dalam membantu pengembangan Pulau Pasumpahan ini. Objek Wisata Pulau Angso Duo dapat berkembang dan lebih menigkat lagi. Ikut andilnya Pemerintah dalam pengembangan Pulau ini merupakan langkah yang sangat tepat dilakukan.

Upaya Pemerintah dalam mengembangkan Pulau Angso Duo dengan memberikan kelengkapan fasilitas yang dibutuhkan di Pulau tersebut. Selain diperoleh dari masyarakat, dana anggaran pemasukan juga diperoleh dari Pemerintah daerah dan swasta. Anggaran pemasukan yang diperoleh dari Pemerintah Daerah dan Swasta akan digunakan untuk pengembangan Pulau Pasumpahan. pengembangan Pulau yang dilakukan seperti menambah fasilitas-fasilitas Pulau, menambah wahana permainan serta pembangunan lainnya. 
Tabel 3

Alokasi Aset Pulau Angso Duo Tahun 2015-2017

\begin{tabular}{|c|c|c|c|}
\hline \multirow[t]{2}{*}{ Sumber } & \multicolumn{3}{|c|}{$\begin{array}{l}\text { Pulau Angso Duo } \\
\text { Tahun 2015-2017 }\end{array}$} \\
\hline & 2015 & 2016 & 2017 \\
\hline Pmt & 75.000 .000 & 60.000 .000 & 150.000 .000 \\
\hline Swt & 100.000 .000 & 97.000 .000 & 145.000 .000 \\
\hline Masy & 53.000 .000 & 120.000 .000 & 100.000 .000 \\
\hline & 228.000 .000 & 277.000.000 & 395.000 .000 \\
\hline
\end{tabular}

Sumber: Dinas Pariwisata Kota Pariaman, 2017

Pada tahun 2015 pemasukan anggaran yang diperoleh sebanyak Rp. 228.000.000. Kemudian pada tahun 2016 anggaran pemasukan yang diperoleh meningkat sebesar Rp. 235.000.000. Pada tahun 2017 pemasukan anggaran yang diperoleh sebesar Rp.595.000.000. Pulau Angso Duo memiliki peningkatan anggaran pemasukan dari tahun 2015-2017.

Anggaran pemasukan yang diperoleh dari Pemerintah merupakan hasil kunjungan wisatawan yang datang. Dengan semakin banyaknya wisatawan berkunjung maka semakin besar pula anggaran pemasukan yang diperoleh. Selain dari itu, anggaran pemasukan yang diperoleh dari Swasta merupakan hasil kerjasama yang dilakukan pihak Pemerintah Daerah dan Swasta guna untuk pengembangan Pulau Angso Duo tersebut. kerjasama yang dilakukan Pemerintah Daerah dan Swasta merupakan hasil dari promosi yang di sebarkan melalui website, dan media sosial.
Tabel 4

Anggaran Pemasukan Pulau Angso Duo

\begin{tabular}{|c|c|c|c|c|}
\hline $\begin{array}{l}\text { Sumber } \\
\text { Dana } \\
\text { Anggaran }\end{array}$ & $\begin{array}{c}\text { Dana } \\
\text { Anggaran }\end{array}$ & $\begin{array}{c}\text { Aset Pulau } \\
\text { Pasumpahan }\end{array}$ & Jumlah & Harga \\
\hline \multirow[t]{2}{*}{ Pmt } & \multirow[t]{2}{*}{60.000 .000} & $\begin{array}{l}\text { Speed } \\
\text { Boat }\end{array}$ & $2 \mathrm{bh}$ & 46.000 .000 \\
\hline & & Mesin $40 \mathrm{PK}$ & $1 \mathrm{bh}$ & 14.000 .000 \\
\hline \multirow[t]{3}{*}{ Sws } & \multirow[t]{3}{*}{120.000 .000} & $\begin{array}{l}\text { Banana } \\
\text { Boat }\end{array}$ & $6 \mathrm{bh}$ & 93.000 .000 \\
\hline & & Pelampung & $40 \mathrm{bh}$ & 8.800 .000 \\
\hline & & $\begin{array}{l}\text { Promosi(FB, } \\
\text { Twitter, Blog) }\end{array}$ & & 18.200 .000 \\
\hline \multirow[t]{2}{*}{ Masy } & \multirow[t]{2}{*}{45.000 .000} & $\begin{array}{l}\text { Promosi } \\
\text { (instragram, } \\
\text { brodur) }\end{array}$ & & 7.000 .000 \\
\hline & & Jet ski & $2 \mathrm{bh}$ & 38.000 .000 \\
\hline \multirow[t]{3}{*}{ Pmt } & \multirow[t]{3}{*}{150.000 .000} & Flying fish & $5 \mathrm{bh}$ & 23.000 .000 \\
\hline & & $\begin{array}{l}\text { Donat } \\
\text { Boat }\end{array}$ & $3 \mathrm{bh}$ & 70.500 .000 \\
\hline & & $\begin{array}{l}\text { Pengina } \\
\text { pan }\end{array}$ & $2 \mathrm{bh}$ & 56.500 .000 \\
\hline \multirow[t]{3}{*}{ Sws } & \multirow[t]{3}{*}{180.000 .000} & $\begin{array}{l}\text { Pengina } \\
\text { pan }\end{array}$ & $3 \mathrm{bh}$ & 11.300 .000 \\
\hline & & $\begin{array}{l}\text { Speed } \\
\text { Boat }\end{array}$ & $3 \mathrm{bh}$ & 69.000 .000 \\
\hline & & Tenda & 60bh & 99.700 .000 \\
\hline \multirow[t]{4}{*}{ Masy } & \multirow[t]{4}{*}{70.000 .000} & Bangku & $8 \mathrm{bh}$ & 19.000 .000 \\
\hline & & Toilet & $4 \mathrm{bh}$ & 22.000 .000 \\
\hline & & Mushola & $1 \mathrm{bh}$ & 13.000 .000 \\
\hline & & Promosi & & 16.000 .000 \\
\hline \multirow[t]{4}{*}{ Pmt } & \multirow[t]{4}{*}{175.000 .000} & Pelampung & 70bh & 15.400 .000 \\
\hline & & $\begin{array}{l}\text { Speed } \\
\text { Boat }\end{array}$ & $2 \mathrm{bh}$ & 46.000 .000 \\
\hline & & Tenda & 40bh & 66.000 .000 \\
\hline & & Jet ski & $3 \mathrm{bh}$ & 47.000 .000 \\
\hline \multirow[t]{5}{*}{ Sws } & \multirow[t]{5}{*}{170.000 .000} & $\begin{array}{l}\text { Pengina } \\
\text { pan }\end{array}$ & $3 \mathrm{bh}$ & 11.300 .000 \\
\hline & & Toilet & $4 \mathrm{bh}$ & 22.000 .000 \\
\hline & & Promosi & & 18.000 .000 \\
\hline & & $\begin{array}{l}\text { Speed } \\
\text { boad }\end{array}$ & $3 \mathrm{bh}$ & 69.000 .000 \\
\hline & & $\begin{array}{l}\text { Mesin } \\
40 \mathrm{PK}\end{array}$ & $3 \mathrm{bh}$ & 49.000 .000 \\
\hline \multirow[t]{6}{*}{ Masy } & \multirow[t]{6}{*}{550.000 .000} & $\begin{array}{l}\text { Donat } \\
\text { Boat }\end{array}$ & $8 \mathrm{bh}$ & 11.750 .000 \\
\hline & & Banana Boat & $4 \mathrm{bh}$ & 62.000 .000 \\
\hline & & Jet ski & $4 \mathrm{bh}$ & 62.700 .000 \\
\hline & & $\begin{array}{l}\text { Flying } \\
\text { Fish }\end{array}$ & $5 \mathrm{bh}$ & 23.000 .000 \\
\hline & & $\begin{array}{l}\text { Water } \\
\text { Dohut }\end{array}$ & & 45.000 .000 \\
\hline & & $\begin{array}{l}\text { Water } \\
\text { Bufterfly }\end{array}$ & & 35.000 .000 \\
\hline
\end{tabular}




\section{Grafik 2 \\ Jumlah Kunjungan Pulau Angso \\ Duo Tahun 2015-2017}

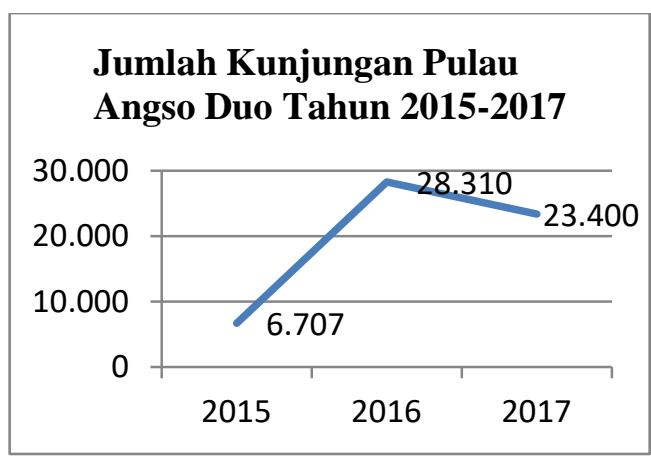

Tabel 5

Perbandingan Trend Dana Anggaran

Pulau Pasumpahan dan

Pulau Angso Duo

\begin{tabular}{|c|c|c|c|c|}
\hline Tahun & $\begin{array}{l}\text { Pulau } \\
\text { Pasumpahan }\end{array}$ & $\%$ & $\begin{array}{c}\text { Pulau Angso } \\
\text { Duo }\end{array}$ & $\%$ \\
\hline 2015 & 225.000 .000 & - & 228.000 .000 & - \\
\hline 2016 & 400.000 .000 & 56,25 & 277.000 .000 & 82,31 \\
\hline 2017 & 895.000 .000 & 44,69 & 395.000 .000 & 70,12 \\
\hline
\end{tabular}

Dari tabel diatas, anggaran pemasukan Pulau Pasumpahan dan Pulau Angso Duo memiliki peningkatan setiap tahunnya. Pada tahun 2015 anggaran pemasukan yang diperoleh Pulau Pasumpahan sebesar Rp. 225.000.000 sedangkan pada Pulau Angso Duo sebesar Rp. 228.000.000. Kemudian, dilihat pada tahun 2016 anggaran pemasukan Pulau Pasumpahan meningkat menjadi Rp. 400.000.000 sedangkan pada pulau Angso Duo sebesar Rp. 277.000.000. Pada tahun 2017 anggaran pemasukan Pulau Pasumpahan menjadi Rp. 895.000.000 sedangkan pada Pulau Angso Duo sebesar Rp. 395.000.000.
Alokasi Aset Pulau Pasumpahan dan Pulau Angso Duo

Anggaran pemasukan yang diperoleh dipergunakan sangat baik oleh pemerintah dan pengelola Pulau Pasumpahan dan Pulau Angso Duo. Dengan cara memberikan kelengkapan fasilitas guna untuk mengembangkan Objek Wisata tersebut. Fasilitas yang terdapat pada Pulau Pasumpahan seperti bangku tempat bersantai, kamar bilas, lapangan volli, camping ground, musshola. Semua fasilitas yang ada untuk menarik perhatian para wisatawan untuk berkunjung ke Pulau tersebut. Sehingga semakin meningkat jumlah kunjungan yang ada maka semakin meningkat pula anggaran pemasukan yang diterima.

Sedangkan fasilitas yang ada pada Pulau Angso Duo yaitu, dermaga terapung, penginapan, pos jaga, kamar bilas. dilihat dari fasilitas yang ada, ini membuktikan bahwa anggaran pemasukan Pulau Pasumpahan dan Pulau Angso Duo dikelola dengan baik dan semestinya untuk pengembangan masing-masing pulau. 
Tabel 6

Fasilitas Pada Pulau Pasumpahan dan Pulau Angso Duo

Tahun 2015-2017

\begin{tabular}{cccc}
\hline \multicolumn{2}{c}{ Pulau Pasumpahan } & \multicolumn{2}{c}{ Pulau Angso Duo } \\
\hline Aset & Tahun & Aset & Tahun \\
\hline $\begin{array}{c}\text { Bangku Tempat } \\
\text { Bersantai }\end{array}$ & 2015 & $\begin{array}{c}\text { Dermaga } \\
\text { Terapung }\end{array}$ & 2015 \\
\hline Kamar Bilas & $\begin{array}{c}2016 \text { dan } \\
2017\end{array}$ & Penginapan & 2016 \\
\hline Lapangan Volli & 2015 & Pos Jaga & 2015 \\
\hline $\begin{array}{c}\text { Camping } \\
\text { Ground }\end{array}$ & 2015 & Kamar Bilas & 2015 \\
\hline Musshola & 2015 & $\begin{array}{c}\text { Jalan } \\
\text { Setapak }\end{array}$ \\
\hline Penginapan & 2015 & & 2015 \\
\hline
\end{tabular}

PENUTUP

Kesimpulan

Anggaran pemasukan menurut persentase lebih besar Pulau Angso Duo dari pada Pulau Pasumpahan sedangkan menurut anggaran pemasukan lebih besar Pulau Pasumpahan dari pada Angso Duo.

Alokasi aset Pulau Pasumpahan berjumlah enam aset sedangkan Alokasi aset Pulau Angso Duo berjumlah lima aset.

\section{Saran}

Kepada Pemerintah, agar lebih meningkatkan lagi upaya untuk pengembangan Pulau Pasumpahan dan Pulau Angso Duo dengan melengkapi fasilitas yang ada.

Kepada Pengelola Pulau, agar lebih menjaga dan mengelola Pulau dengan baik.

Kepada Masyarakat, agar lebih menjaga lingkungan saat berwisata ke Pulau.

\section{DAFTAR PUSTAKA}

Bakaruddin, 1990. Geografis Pariwisata dan Permasalahannya. IKIP Padang.

Gamal, Suwantoro.1997.Dasar-dasar Pariwisata.Yogyakarta: Andi

Jamaris.1991.Respon Masyarakat Terhadap Pengembangan Objek Wisata di SUMBAR dalam Kaitannya dengan Status Sosial Budaya. IKIP Padang.

Kohyat,H.1980.Sejarah Pariwisata dan Perkembangan di Indonesia.Jakarta:

Gramedia Rasindo

Kosasih.1987.Diperlukannya

Pengelolaan Pariwisata

Diseluruh Tanah Air. Jakarta:Harian Terbit.

Muljadi A.J. 2009.

Kepariwisataan dan

Perjalanan. Jakarta:

Rajawali Pers.

Suryobroto.1990.Perkembangan

Kepariwisataan. Jakarta:

Rineka Cipta.

Suwantoro. 1997. Dasardasar Pariwisata.

Yogyakarta: Andi

Shim, Jae K. 2000. Akutansi

Manajemen. Jakarta:

Rineka Cipta

Wihoho.1990.Pariwisata

Citra dan Manfaatnya. Jakarta:Bina Rena Pariwisata.

Yoetti,Oka.1997.Perencanaan dan Pengembangan

Pariwisata.Jakarta:PT Prandnya Paramita. 